\section{Banish cronyism}

\section{A Texas cancer-research fund needs big fixes to restore badly eroded trust.}

$\mathrm{W}$ hat a window into reality one misdirected e-mail can provide. Jimmy Mansour, head of the governing board at the Cancer Prevention and Research Institute of Texas (CPRIT) in Austin, mistakenly hit 'reply all' on a missive he sent last week, celebrating the resignations of many of the institute's scientific peer reviewers. The e-mail, first publicized by the Houston Chronicle, makes clear that Mansour, an accountant, lawyer and telecommunications entrepreneur, views scientists and scientific review with breathtaking disdain. "Better to get them all out of the way now," Mansour wrote following yet another of the letters of resignation tendered to the CPRIT in recent weeks by at least 29 of the institute's first-rate scientific reviewers. The letters were written in solidarity with the very public departure from the CPRIT of Nobel laureate Alfred Gilman, who until two weeks ago was the institute's chief scientific officer.

Gilman had given up on a review process that he labelled as corrupted by cronyism and unduly influenced by "really evil" political appointees on the CPRIT's governing board, motivated by regional Texas rivalries and personal interest. For instance, several grants to scientists at the University of Texas Southwestern Medical Center at Dallas, easily the best biomedical research institution in the state, were shelved by CPRIT leaders early this year despite strong endorsement from scientific reviewers. At the same time, a business-incubator grant was speedily awarded without scientific review: US\$18 million went to the University of Texas MD Anderson Cancer Center and \$2 million to Rice University, both in Houston. After Gilman and the chairs of all eight of the CPRIT's scientific-review panels complained, the incubator grant was pulled back, and the institute said that a scientific-review panel and commercial reviewers would all need to agree that it passed muster. It hired a compliance officer and, in August funded the shelved grants.
An outside observer could have been forgiven for surmising that with these last three actions, the institute was mending its ways and beginning a new chapter. But then, as we report on page 459 , came Mansour's e-mail, written to CPRIT executive director William Gimson on 14 October, two days after Gilman's departure.

The exodus of scientific reviewers "gives us the prime opportunity to announce a new regime", wrote Mansour. "There will be a number of Texas Institutions who will be ecstatic." If the CPRIT concentrates on positive messaging at a conference this week, he added, "Gilman and the regime of the old guard (of research) will get the message" that the
"The CPRIT's change at the very highest levels." leadership must institute is moving forward. Forward towards what? His words give little confidence that the goal is a process that will judge science purely on its merits.

Mansour would make an almost comic villain were the stakes not so high. He is responsible for the $\$ 3$ billion that more than $60 \%$ of voting Texans approved in 2007 to fight cancer over ten years; his term at the head of the governing board does not expire until 2015.

Yet it is clear that, if the institute hopes to recruit independent peer reviewers of the calibre that have just departed in droves, its leadership must change at the very highest levels. Mansour's removal is essential; at least one ethicist has suggested that Gimson should go as well. Such housecleaning is also the only way to begin rebuilding the trust of the Texas public, which has every right to expect that the $\$ 2$ billion as yet unspent by the CPRIT be awarded through unimpeachable peer review. After all, when they voted five years ago, Texans authorized the state to borrow $\$ 3$ billion "for research in Texas to find the causes of and cures for cancer". They did not vote for awards to bypass scientific scrutiny, for cronyism or for the equal distribution of grants between Texas institutions, regardless of the quality of proposed projects.

Happily, the citizens of the state still have some leverage. A vote of the state legislature is required every year to issue the annual $\$ 300$ million in funding that supports the CPRIT. Texans should insist that their state politicians make future funding contingent on a serious clean-up, and on the re-implementation of top-calibre peer review for every single project that the CPRIT funds.

\section{Shock and law}

\section{The Italian system's contempt for its scientists is made plain by the guilty verdict in L'Aquila.}

CC 'm not crazy. I know they can't predict earthquakes," the Italian public prosecutor Fabio Picuti told Nature last year. He was speaking as the manslaughter trial began in the ruined town of L'Aquila of six scientists and one government official for their alleged role in the deaths of 309 people in the quake of April 2009 (see Nature 477, 264-269; 2011). On Monday evening, the seven were found guilty and sentenced to six years in prison (see Nature http://doi.org/jkp; 2012). The verdict is perverse and the sentence ludicrous. Already some scientists have responded with warnings about the chilling effect on their ability to serve in public risk assessments.

Even Picuti was surprised. He had requested a prison term of four years. "We'll have to read the judge's motivations to understand why," he said. Under Italian law, judge Marco Billi has up to three months to reveal his reasoning.

Despite the way the verdict has been portrayed in the media as an attack on science, it is important to note that the seven were not on trial for failing to predict the earthquake. As members of an official risk commission, they had all participated in a meeting held in L'Aquila on 31 March 2009, during which they were asked to assess the risk of a major earthquake in view of the many tremors that had hit the city in the previous months, and responded by saying that the earthquake risk was clearly raised but that it was not possible to offer a detailed prediction. The meeting was unusually quick, and was followed by a press conference at which the Civil Protection Department and local authorities reassured the population, stating that minor shocks did not increase the risk of a major one.

According to the prosecutor, such reassurances led 29 victims who would otherwise have left L'Aquila in the following days to change their minds and decide to stay; they died when their homes collapsed. The prosecutor thus reasoned that the "inadequate" risk assessment of the expert panel led to scientifically incorrect messages being given to the public, which contributed to a higher death count.

The seven - Bernardo De Bernardinis, Enzo Boschi, Giulio Selvaggi, Franco Barberi, Claudio Eva, Mauro Dolce and Gian Michele Calvi - are appealing against the verdict. They will remain free until the appeals process is finished, which could take years.

That provides an opportunity. There will be time enough to ponder the wider implications of the verdict, but for now all efforts should be channelled into protest, both at the severity of the sentence and at scientists being criminalized for the way their opinions were communicated. Science has little political clout in Italy and the trial proceeded $\rightarrow$ NATURE.COM To comment online, click on Editorials at: go.nature.com/xhunqu in an absence of informed public debate that would have been unthinkable in most European countries or in the United States. Billi should promptly explain his decision, and the scientific community should promptly challenge it. - 